\title{
Advances and challenges in enveloped virus-like particle (VLP)-based vaccines
}

\author{
Shiyu Dai', Hualin Wang', Fei Deng ${ }^{1 *}$ \\ 'State Key laboratory of Virology, Wuhan Institute of Virology, Chinese Academy of Sciences, Wuhan, 430071, China.
}

\section{Article Info}

\section{Article Notes}

Received: January 19, 2018

Accepted: April 25, 2018

\section{*Correspondence:}

Dr. Fei Deng, Wuhan Institute of Virology, Chinese Academy of Sciences Xiaohongshan 44\#, Wuchang District, Wuhan

city, Hubei Province, 430071

P. R. China;

Telephone: 86-27-87198465,

E-mail: df@wh.iov.cn

C 2018 Deng F. This article is distributed under the terms of the Creative Commons Attribution 4.0 International License.

\section{Key words}

Virus-like particle (VLP)

Enveloped virus,

Vaccine

\section{ABSTRACT}

Virus-like particles (VLPS) are highly organized particles that self-assemble from viral structural proteins. Like parental viruses, VLPs can be either non-enveloped or enveloped and can be produced in different expression systems depending on their complexity. Over the last three decades, VLPS have developed as a high-priority alternative to traditional vaccines against infectious pathogens due to their safety, simplicity and favorable immunological characteristics to induce both humoral and cellular immune responses. Most of emerging and re-emerging viruses that pose a continuous threat to human health are enveloped, but few vaccines are currently available. Advances in expression technology for complex, enveloped VLPs provide new possibilities to develop potent vaccines against pathogenic enveloped viruses. This review describes major progress and challenges in the production of enveloped VLPS, with respect to the main principles in the assembly and budding process, factors that need to be taken into account for the design strategies and choice of relevant production platforms.

\section{Introduction}

Vaccination remains the most cost-effective approach in preventing and controlling infectious viruses which pose a threat to global public health. The currently available preventative viral vaccines are mainly based on inactivated or live attenuated viruses and have shown good efficacy at inducing protective immunity and played an important role in the control or localized eradication of infectious diseases ${ }^{1}$. Nevertheless, conventional vaccines have several drawbacks such as safety issues and deviation of the protective immune responses ${ }^{2}$, so safer and more efficient vaccines are in urgent need.

Virus-like particles (VLPs) have been exploited as an alternative to traditional vaccines. VLPs are non-infectious nanostructures composed of viral structural proteins morphologically resembling authentic virions. Based on the structure of viruses, VLPs can be divided into non-enveloped VLPs and enveloped VLPs (eVLPs) ${ }^{3}$. VLP-based vaccines are considered safer than inactivated or attenuated viruses because a potential incomplete inactivation and reversion of the virus are avoided. They also offer advantages over other subunit vaccines because of their self-adjuvanting properties ${ }^{4}$. Firstly, VLPs have an optimal size (20 to $200 \mathrm{~nm}$ ) and particulate structure, so they can be easily recognized and absorbed by antigen presenting cells. Secondly, VLPs can be produced in a range of 
Table 1. Representative licensed recombinant VLP-based human vaccines.

\begin{tabular}{|c|c|c|c|c|c|}
\hline Target virus & Vaccine name & Company/institution & Year of licensure & Expression system & Refenrence \\
\hline HBV (Hepatitis B virus) & Engerix- $\mathrm{B}^{\circ}$ & GlaxoSmithKline & 1986 & Yeast & Keating et al. $(2003)^{5}$ \\
\hline HPV (human papillomavirus) & $\begin{array}{l}\text { Gardasi } \\
\text { Cervarix }^{\circ}\end{array}$ & $\begin{array}{c}\text { Merck \& Co. } \\
\text { GlaxoSmithKline }\end{array}$ & $\begin{array}{l}2006 \\
2009\end{array}$ & $\begin{array}{l}\text { Yeast } \\
\text { Insect }\end{array}$ & $\begin{array}{l}\text { Villa et al. }(2005)^{17} \\
\text { Harper et al. }(2004)^{21}\end{array}$ \\
\hline HEV (hepatitis E virus) & Hecolin1 & Xiamen Innovax Biotech Co. & 2011 & E.coli & Li et al. $(2005)^{29}$ \\
\hline
\end{tabular}

production systems and this provides flexibility in tailoring manufacturing conditions.

Since the first recombinant VLP-based vaccine, yeastproduced HBsAg vaccine (Engerix- $B^{\circledR}$ ), was approved by the Food and Drug Administration (FDA) ${ }^{5}$, hundreds of VLP-based vaccine candidates have been studied, and some have been shown to be efficacious in preclinical and clinical trials. However, only a few of VLP-based vaccines have reached the market as summarized in Table 1 and most of them are targeting non-enveloped viruses. In contrast to non-enveloped VLPs, eVLPs are much more complex in composition. The presence of a host cell-derived membrane provides additional possibilities to integrate heterogonous antigens and adjuvants, but also potential challenges in regulatory approval due to the uncertainty of host cell components. In addition, for different virus families, the origin and composition of envelope vary and usually depend on the virion assembly process in the natural host and the specific cell line used for production. Challenges remain to produce eVLPs with optimal quality, stability and good immunogenicity at high yield.

This review, therefore, discusses the achievements and challenges of the development of eVLP-based vaccines.

\section{Assembly and budding of eVLPs}

Formation of virus always requires the presence of all components including viral genome, inner structural proteins, and glycoproteins, but the minimal requirements that drive eVLP formation are not well understood6. Generally, self-assembly of eVLPs includes two steps, namely inner structural protein (core, capsid or matrix) formation and then membrane enclosure for further budding.

Assembly and budding of eVLPs may be dependent on viral inner structural protein, envelope glycoproteins or both $^{7}$. In retroviruses, expression of the gag core particle alone can direct eVLP formation and budding ${ }^{8}$. For coronavirus or flavivirus, expression of glycoproteins leads to release of eVLPs morphologically similar to complete virions $^{9,10}$.

Viral surface antigens, mainly glycoproteins, will be present in the envelope of eVLP, possibly enhancing immunogenicity and acting as an adjuvant. The proper folding, especially glycosylation of these viral antigens plays an important role in the efficacy of eVLP-based vaccines as it is critical for stability, immune recognition, and pathogenicity ${ }^{11}$. For example, mutant Zika virus that lacks the $\mathrm{N}$-glycosylation of $\mathrm{E}$ protein is attenuated at mammalian and mosquito host ${ }^{12}$. Glycosylation of $\mathrm{E}$ protein also is a major determinant for viral pathogenesis of Dengue virus (DENV) ${ }^{13}$ and the secretion of tick-borne encephalitis virus (TBEV) VLPs ${ }^{14}$.

Like enveloped viruses, eVLPs get the lipid membrane from the host cells through budding. Many viruses including retroviruses, filoviruses, alphaviruses, ortho- and paramyxoviruses are released directly from the cell surface if budding occurs at the plasma membrane. However, for some viruses including flaviviruses and bunyaviruses, budding can also occur on intracellular membranes along the secretory pathway, resulting in the accumulation of virus particles in the lumen of cellular organelles ${ }^{7}$. Depending on the virion assembly process in the natural host, intracellular membrane compartments or some alternative pathway may be involved in secretory of eVLPs.

Efforts to investigate virus budding mechanisms will increase understanding of the formation of eVLP and accelerate the development of eVLP.

\section{Expression platforms for eVLPs}

The comparison of the bacteria, yeast, insect, mammalian and plant expression systems and production of several eVLP-based vaccine candidates tested in preclinical trials are summarized in Table 2 and Table 3.

Bacteria are the most widely used expression system for manufacturing recombinant proteins, but not a proper platform for eVLP production due to a lot of factors, including the lack of a post-translational modification (PTM) system and protein solubility problems ${ }^{15}$.

Eukaryotic expression systems are more suitable for the production of eVLP. Yeast expression systems, especially those based on Saccharomyces cerevisiae and Pichia pastoris, have advantages such as scalable fermentation, low production costs, and PTM process ${ }^{16}$. Two licensed vaccines, the HBV vaccine Engerix- ${ }^{\circledR}$ and HPV vaccine Gardasil $^{\circledR}$ have been manufactured using this system ${ }^{5,17}$. Despite the successes, the system has some limitations, such as the different PTM of proteins from mammalian cells and it is generally used for the production of nonenveloped VLPs. Nevertheless, recently its application has been extended to the production of eVLPs. Secretory expression of enveloped human immunodeficiency virus-1 (HIV-1) Gag VLPs using Saccharomyces cerevisiae 
Table 2. Comparison of different VLP production platforms.

\begin{tabular}{|l|c|c|c|c|c|}
\hline \multicolumn{1}{|c|}{ VLP type } & Bacteria & $\begin{array}{c}\text { Yeast } \\
\text { Non-enveoped } \\
\text { Enveoped }\end{array}$ & $\begin{array}{c}\text { Insect cells } \\
\text { Non-enveoped } \\
\text { Enveoped }\end{array}$ & $\begin{array}{c}\text { Mammalian cells } \\
\begin{array}{c}\text { Non-enveoped } \\
\text { Enveoped }\end{array}\end{array}$ & $\begin{array}{c}\text { Non-enveoped } \\
\text { Enveoped }\end{array}$ \\
\hline Secretory expression & - & + & ++ & ++ & + \\
\hline Speed & +++ & +++ & ++ & ++ \\
\hline Cost & + & + & ++ & ++ & ++ \\
\hline Scalability & +++ & +++ & ++ & ++ \\
\hline Yield & +++ & ++ & ++ & ++ \\
\hline VLP complexity & + & ++ & +++ & + & ++ \\
\hline
\end{tabular}

- , no successful cases reported; +, low; ++, medium; +++, high

Table 3. Production of eVLPs in different expression systems.

\begin{tabular}{|c|c|c|c|c|}
\hline Family & Virus & Determinant protein & Expression system & Refenrence \\
\hline Retroviridae & Human immunodeficiency virus I & Gag, Env & $\begin{array}{c}\text { Yeast (Saccharomyces cerevisiae) } \\
\text { Insect (Sf9) } \\
\text { Insect (S2) } \\
\text { Mammalian cell (293T) } \\
\text { Plant (Nicotiana benthamiana) }\end{array}$ & $\begin{array}{l}\text { Sakuragi et al. }(2002)^{8} \\
\text { Lynch et al. }(2010)^{30} \\
\text { Yang et al. }(2012)^{31} \\
\text { Crooks et al. }(2007)^{32} \\
\text { Meyers et al. }(2008)^{33}\end{array}$ \\
\hline Orthomyxoviridae & Influenza virus A & $\mathrm{HA}, \mathrm{NA}, \mathrm{M} 1, \mathrm{M} 2$ & $\begin{array}{c}\text { Insect (Sf9, High Five) } \\
\text { Mammalian cell (Vero) } \\
\text { Plant (Nicotiana benthamiana) }\end{array}$ & $\begin{array}{c}\text { Krammer et al. }(2007)^{34} \\
\text { Wu et al. }(2010)^{35} \\
\text { D'Aoust et al. }(2008)^{36}\end{array}$ \\
\hline Togaviridae & Chikungunya virus (CHIKV) & $C, E 3, E 2,6 k, E 1$ & $\begin{array}{l}\text { Yeast (Pichia pastoris) } \\
\text { Insect (Sf21) } \\
\text { Mammalian cell (293T) }\end{array}$ & $\begin{array}{l}\text { Saraswat et al. }(2016)^{37} \\
\text { Metz et al. }(2013)^{38} \\
\text { Akahata et al. }(2013)^{39}\end{array}$ \\
\hline Coronaviridae & $\begin{array}{l}\text { Severe acute respiratory syndrome } \\
\text { (SARS) }\end{array}$ & $S, E, M, N$ & Insect (Sf9) & Mortola et al. $(2013)^{9}$ \\
\hline Paramyxoviridae & Nipah virus & $M, G, F$ & $\begin{array}{l}\text { Yeast (Pichia pastoris) } \\
\text { Mammalian cell (293T) }\end{array}$ & $\begin{array}{l}\text { Joseph et al. }(2016)^{40} \\
\text { Walpita et al. }(2011)^{41}\end{array}$ \\
\hline Filoviridae & Ebola virus & VP40, GP, NP & $\begin{array}{c}\text { Insect (Sf9) } \\
\text { Mammalian cell (293T) }\end{array}$ & $\begin{array}{c}\text { Sun et al. }(2009)^{42} \\
\text { Warfield et al. }(2007)^{43}\end{array}$ \\
\hline Flaviviridae & Dengue virus & prM, E & $\begin{array}{l}\text { Yeast (Pichia pastoris) } \\
\text { Insect (Sf9) } \\
\text { Mammalian cell (COS-1) } \\
\text { Mammalian cell (293T) } \\
\text { Plant (lettuce) }\end{array}$ & $\begin{array}{l}\text { Liu et al. }(2009)^{44} \\
\text { Kuwahara et al. }(2010)^{45} \\
\text { Chang et al. }(2003)^{27} \\
\text { Zhang et al. }(2011)^{10} \\
\text { Kanagaraj et al. }(2011)^{46}\end{array}$ \\
\hline Phenuiviridae & Rift Valley fever virus (RVFV) & Gn, Gc, NP & $\begin{array}{c}\text { Insect (S2) } \\
\text { Insect (Sf21, Sf9) } \\
\text { Mammalian cell (293T) }\end{array}$ & $\begin{array}{l}\text { de Boer et al. }(2010)^{22} \\
\quad \text { Liu et al. }(2008)^{47} \\
\text { Habjan et al. }(2009)^{48}\end{array}$ \\
\hline Arenaviridae & Lassa virus (LASV) & GPC, NP, Z & $\begin{array}{l}\text { Mammalian cell (293T/17) } \\
\text { Mammalian cell (MDCK- II) }\end{array}$ & $\begin{array}{l}\text { Branco et al. }(2010)^{49} \\
\text { Schlie et al. }(2010)^{50}\end{array}$ \\
\hline
\end{tabular}

spheroplasts has been achieved ${ }^{8}$. However, in the case of HIV-2, Saccharomyces cerevisiae cells fail to support the multimerization of the Gag protein into VLPs and particle budding from the membran $\mathrm{e}^{18}$. Therefore, it is important to note that yeast is not always suitable for eVLP production.

Higher eukaryotic expression systems, insect and mammalian cells, perform more complex PTM and support most aspects of the virus life cycle. So, they have been extensively used for both intracellular and secretory production of eVLPS.

The baculovirus-insect cell expression system (BVES) is the most commonly used system for producing a wide variety of eVLPs as summarized in Table 3 . The most commonly used insect cell lines are derived from
Spodoptera frugiperda (Sf9 and Sf21) and Trichoplusia ni (Tn5, commercially known as High Five $^{\mathrm{TM}}$ ), which grow optimally at $27^{\circ} \mathrm{C}$ and do not require CO2, making scale up of protein production feasible ${ }^{19,20}$. A licensed HPV vaccine Cervarix $^{\circledR}$ has been manufactured using this system ${ }^{21}$. However, some issues limit the application of this system for eVLP production. One limitation is the yields of secreted and membrane-bound proteins are often low, probably because of the side effects of baculovirus infection on the secretory machinery of host insect cells. Furthermore, lepidopteran cells are unable to produce glycoproteins with structurally authentic mammalian N-glycans. Another main disadvantage is contamination of progeny baculovirus ${ }^{19}$. Stably transformed insect cells have emerged as attractive alternatives, particularly for the production of secreted 
glycoproteins. The Drosophila melanogaster Schneider 2 (S2) cell line, has been widely used. It allows inducible expression and secretion of soluble glycoproteins under non-lytic conditions and serum-free medium ${ }^{20}$. Rift Valley fever (RVFV) VLP composed of Gn and Gc glycoproteins has been obtained using S2 cell line ${ }^{22}$.

The mammalian cell is another platform that can produce both non-enveloped and enveloped VLPs. The ability to perform complete PTMs of recombinant proteins is the main advantage of mammalian cells. Several mammalian cell types, such as human embryonic kidney 293 (HEK293), Chinese hamster ovary (CHO) and baby hamster kidney (BHK-21) cell lines are extensively utilized for eVLP production. Based on these cell lines, most of the eVLP-based vaccines have been studied as summarized in Table 3. However, the high production cost, low protein yield, and potential safety concerns resulted from contamination by adventitious agents impose restrictions on commercialization of mammalian $\mathrm{VLPs}^{23}$.

Plant expression systems have also been used for VLP production. A plant can produce large quantities of recombinant protein at low cost, provide complex but distinctive PTM, and bring a low-risk of introducing adventitious human pathogens ${ }^{24}$. Many plant species have been used for recombinant protein production, e.g., tobacco, potato, carrot, and tomato. Although plant-specific glycans provide a unique advantage for producing eVLPs with high immunogenicity and the protein synthesis and folding pathway are conserved between animals and plants, there are some differences in protein glycosylation. The improper glycoforms may reduce efficacy or cause potential adverse effects.

\section{Challenges and solutions in the development of eVLPs}

Technical challenges still remain in the manufacture of eVLP-based vaccines, regarding the design, purification, and storage.

Firstly, the stability of the VLP-based vaccine is one of the most significant issues. VLPs are multimeric structures that are generally more stable than subunit vaccines, however, the lack of the viral genome makes them unstable when the conditions change, especially during downstream processing (DSP) ${ }^{25}$. Generally, eVLPs having a host-derived envelop are more sensitive to the external environment than the protein-only VLPs. Variations in conditions, e.g., temperature, shear force and chemical treatment can destroy the integrity and stability of the particles, this structural destruction further leads to the reduction in immunogenicity of eVLPs. In some cases, VLPs have been modified in order to improve particle thermostability. One common technique is the introduction of the stabilizing mutations. A study of poliovirus type 3 VLPs shows that
VLPs having stabilizing mutations within the coat proteins retain the native antigenic conformation and the repetitive structure of the original virus particle and are more stable than the wild type VLPs ${ }^{26}$.

Secondly, the expression level of viral proteins in different platforms vary considerably. In general, the secretory expression of glycoproteins is difficult. Since budding from cell membrane to get envelop is a key step during the eVLP formation process, if eVLP is not efficiently secreted, a cell lysis or other extraction step might be required, and these steps increase the difficulty for further purification. A common way to improve expression level of transmembrane glycoproteins is to delete or replace the transmembrane region which anchors the protein in the membrane. Replacement of the stem-transmembrane domain of DENV2 E protein which contains a strong ER retention signal with the corresponding region of japanese encephalitis virus (JEV) provides extracellular secretion of eVLPs ${ }^{27}$. This is not always useful, for instance, if membrane-integration dependent oligomerization is required for functionality or immunogenicity. Another way to improve the secretion potential for eVLP is the introduction of signal peptide. As for the expression of DENV VLP, cells co-expressing prM and E proteins fail to secret eVLPs. When adding a JEV signal sequence at the $\mathrm{N}$ terminal of prME protein, cells can effectively secret eVLPs, indicating signal peptide is one of the important factors that influence downstream protein translocation and topology ${ }^{10}$. It should be noted that extrinsic signal peptides will change the characteristic of the protein in some cases.

Finally, on the DPS, numerous impurities co-purified with eVLPs pose a daunting challenge. The process-related contaminants are predominantly attributed to host cell impurities such cell debris, host cell proteins, DNA, and lipids. A typical example is the baculovirus from the BVES. The similar biophysical features, e.g., size, electrostatic and architecture between eVLPs and the enveloped baculoviral particles make the DSP complicate. Baculoviruses have shown adjuvant activity and if not removed or inactivated, would induce undesirable synergistic effects ${ }^{19}$. To meet the criteria on the security issue, purified eVLPs should be inactivated to eliminate baculovirus infectivity, but this strategy may affect the antigenicity of eVLPs. Alternatively, efforts to improve the purity of product by stepwise purification processes including clarification, intermediate purification, and polishing without sacrificing the immunogenicity of eVLPs are more significant. Diverse of purification methods such as centrifugation, precipitation, ultrafiltration and chromatography have been developed ${ }^{28}$.

\section{Conclusion}

VLPs have been developed as an alternative to traditional vaccines based on their safety, flexibility and distinctive immunogenic properties. Challenges 
encountered at the bioprocessing technology and dealing with regulatory issues to bring eVLPs to the market. The further understanding of VLP assemblies and advances in the technologies will lead to the development of a series of novel, stable and efficient eVLP-based vaccine candidates in the near future.

\section{References}

1. Roush SW, Murphy TV. Vaccine Preventable Disease Table Working Group. Historical comparisons of morbidity and mortality for vaccine-preventable diseases in the United States. Jama-Journal of the American Medical Association. 2007; 298(18): p.2155-2163.

2. Ulmer JB, Valley U, Rappuoli R. Vaccine manufacturing: challenges and solutions. Nature Biotechnology. 2006; 24(11): p.1377-1383.

3. Liu J, Dai S, Wang M, et al. Virus like particle-based vaccines against emerging infectious disease viruses. Virologica Sinica. 2016; 31(4): p.279-287.

4. Mohsen MO, Zha L, Cabral-Miranda G, et al. Major findings and recent advances in virus like particle (VLP)-based vaccines. Seminars in Immunology. 2017; 34: p.123-132.

5. Keating GM, Noble S. Recombinant hepatitis B vaccine (Engerix-B (R)) - A review of its immunogenicity and protective efficacy against hepatitis B. Drugs. 2003; 63(10): p.1021-1051.

6. Zlotnick A, Mukhopadhyay S. Virus assembly, allostery and antivirals. Trends in Microbiology. 2011; 19(1): p.14-23.

7. Welsch S, Mueller B, Kraeusslich HG. More than one door - Budding of enveloped viruses through cellular membranes. Febs Letters. 2007; 581(11): p.2089-2097.

8. Sakuragi S, Goto T, Sano K, et al. HIV type 1 Gag virus-like particle budding from spheroplasts of Saccharomyces cerenvisiae. Proceedings of the National Academy of Sciences of the United States of America. 2002; 99(12): p.7956-7961.

9. Mortola E, Roy P. Efficient assembly and release of SARS coronaviruslike particles by a heterologous expression system. Febs Letters. 2004; 576(1-2): p.174-178.

10. Zhang S, Liang $\mathrm{M}, \mathrm{Gu} \mathrm{W}$, et al. Vaccination with dengue virus-like particles induces humoral and cellular immune responses in mice. Virology Journal. 2011; 8: p.333.

11. Rudd PM, Wormald MR, Stanfield RL, et al. Roles for glycosylation of cell surface receptors involved in cellular immune recognition. Journal of Molecular Biology. 1999; 293(2): p.351-366.

12. Fontes-Garfias CR, Shan C, Luo H, et al. Functional Analysis of Glycosylation of Zika Virus Envelope Protein. Cell Reports. 2017; 21(5): p.1180-1190.

13. Bryant JE, Calvert AE, Mesesan K, et al. Glycosylation of the dengue 2 virus E protein at $\mathrm{N} 67$ is critical for virus growth in vitro but not for growth in intrathoracically inoculated Aedes aegypti mosquitoes. Virology. 2007; 366(2): p.415-423.

14. Goto A, Yoshii K, Obara M, et al. Role of the N-linked glycans of the prM and $\mathrm{E}$ envelope proteins in tick-borne encephalitis virus particle secretion. Vaccine. 2005; 23(23): p.3043-3052.

15. Rosano GL, Ceccarelli EA. Recombinant protein expression in Escherichia coli: advances and challenges. Frontiers in Microbiology. 2014; 5: p.172.

16. Kim H, Kim H. Yeast as an expression system for producing virus-like particles: what factors do we need to consider. Lett Appl Microbiol. 2017; 64(2): p.111-123.

17. Villa LL, Costa RLR, Petta CA, et al. Prophylactic quadrivalent human papillomavirus (types $6,11,16$, and 18) L1 virus-like particle vaccine in young women: a randomised double-blind placebo-controlled multicentre phase II efficacy trial. Lancet Oncology. 2005; 6(5): p.271278.

18. Morikawa Y, Goto T, Yasuoka D, etal. Defect of human immunodeficiency virus type 2 Gag assembly in Saccharomyces cerevisiae. Journal of Virology. 2007; 81(18): p.9911-9921.

19. van Oers MM. Opportunities and challenges for the baculovirus expression system. Journal of Invertebrate Pathology. 2011; 107: p.S3-S15.

20. Yamaji H. Suitability and perspectives on using recombinant insect cells for the production of virus-like particles. Applied Microbiology and Biotechnology. 2014; 98(5): p.1963-1970.

21. Harper DM, Franco EL, Wheeler C, et al. Efficacy of a bivalent L1 virus-like particle vaccine in prevention of infection with human papillomavirus types 16 and 18 in young women: a randomised controlled trial. Lancet. 2004; 364(9447): p.1757-1765.

22. de Boer SM, Kortekaas J, Antonis AF, et al. Rift Valley fever virus subunit vaccines confer complete protection against a lethal virus challenge. Vaccine. 2010; 28(11): p.2330-2339.

23. Zhu J. Mammalian cell protein expression for biopharmaceutical production. Biotechnology Advances. 2012; 30(5): p.1158-1170.

24. Chen Q Lai H. Plant-derived virus-like particles as vaccines. Human Vaccines \& Immunotherapeutics. 2013; 9(1): p.26-49.

25. Vicente T, Roldao A, Peixoto C, et al. Large-scale production and purification of VLP-based vaccines. Journal of Invertebrate Pathology. 2011; 107: p.S42-S48.

26. Marsian J, Fox H, Bahar MW, et al. Plant-made polio type 3 stabilized VLPs-a candidate synthetic polio vaccine. Nature Communications. 2017; 8: p.245.

27. Chang GJJ, Hunt AR, Holmes DA, et al. Enhancing biosynthesis and secretion of premembrane and envelope proteins by the chimeric plasmid of dengue virus type 2 and Japanese encephalitis virus. Virology. 2003; 306(1): p.170-180.

28. Peixoto C, Sousa MFQ Silva AC, et al. Downstream processing of triple layered rotavirus like particles. Journal of Biotechnology. 2007; 127(3): p.452-461.

29. Li SW, Zhang J, Li YA, et al. A bacterially expressed particulate hepatitis E vaccine: antigenicity, immunogenicity and protectivity on primates. Vaccine. 2005; 23(22): p.2893-2901.

30. Lynch AG, Tanzer F, Fraser MJ, et al. Use of the piggyBac transposon to create HIV-1 gag transgenic insect cell lines for continuous VLP production. Bmc Biotechnology. 2010; 10: p.30.

31. Yang L, Song Y, Li X, et al. HIV-1 Virus-Like Particles Produced by Stably Transfected Drosophila S2 Cells: a Desirable Vaccine Component. Journal of Virology. 2012; 86(14): p.7662-7676.

32. Crooks ET, Moore PL, Franti M, et al. A comparative immunogenicity study of HIV-1 virus-like particles bearing various forms of envelope proteins, particles bearing no envelope and soluble monomeric gp120. 2007; Virology. 366(2): p.245-262.

33. Meyers A, Chakauya E, Shephard E, et al. Expression of HIV-1 antigens in plants as potential subunit vaccines. Bmc Biotechnology. 2008; 8: p.53.

34. Krammer F, Schinko T, Palmberger D, et al. Trichoplusia ni cells (High Five(TM)) are highly efficient for the production of influenza A viruslike particles: a comparison of two insect cell lines as production platforms for influenza vaccines. Molecular Biotechnology. 2010; 45(3): p.226-234.

35. Wu CY, Yeh YC, Yang YC, et al. Mammalian Expression of Virus-Like Particles for Advanced Mimicry of Authentic Influenza Virus. Plos One. 2010; 5(3): p.e9784. 
36. D’Aoust MA, Lavoie PO, Couture MMJ, et al. Influenza virus-like particles produced by transient expression in Nicotiana benthamiana induce a protective immune response against a lethal viral challenge in mice. Plant Biotechnology Journal. 2008; 6(9): p.930-940.

37. Saraswat S, Athmaram TN, Parida $M$, et al. Expression and Characterization of Yeast Derived Chikungunya Virus Like Particles (CHIK-VLPs) and Its Evaluation as a Potential Vaccine Candidate. Plos Neglected Tropical Diseases. 2016; 10(7); p.e0004782.

38. Metz SW, Gardner J, Geertsema C, et al. Effective Chikungunya Viruslike Particle Vaccine Produced in Insect Cells. Plos Neglected Tropical Diseases. 2013; 7(3): p.e2124.

39. Akahata W, Yang ZY, Andersen H, et al. A virus-like particle vaccine for epidemic Chikungunya virus protects nonhuman primates against infection. Nature Medicine. 2010; 16(3): p.334-338.

40. Joseph NMS, Ho KL, Tey BT, et al. Production of the virus-like particles of nipah virus matrix protein in Pichia pastoris as diagnostic reagents. Biotechnology Progress. 2016; 32(4): p.1038-1045.

41. Walpita P, Barr J, Sherman M, et al. Vaccine Potential of Nipah VirusLike Particles. Plos One. 2011; 6(4): p.e18437.

42. Sun Y, Carrion R, Jr., Ye L, et al. Protection against lethal challenge by Ebola virus-like particles produced in insect cells. Virology. 2009; 383(1): p.12-21.

43. Warfield KL, Swenson DL, Olinger GG, et al. Ebola virus-like particlebased vaccine protects nonhuman primates against lethal Ebola virus challenge. Journal of Infectious Diseases. 2007; 196(Suppl 2): p.S430-S437.
44. Liu W, Jiang H, Zhou J, et al. Recombinant dengue virus-like particles from Pichia pastoris: efficient production and immunological properties. Virus Genes. 2010; 40(1): p.53-59.

45. Kuwahara M, Konishi E. Evaluation of Extracellular Subviral Particles of Dengue Virus Type 2 and Japanese Encephalitis Virus Produced by Spodoptera frugiperda Cells for Use as Vaccine and Diagnostic Antigens. Clinical and Vaccine Immunology. 2010; 17(10): p.15601566.

46. Kanagaraj AP, Verma D, Daniell H. Expression of dengue-3 premembrane and envelope polyprotein in lettuce chloroplasts. Plant Molecular Biology. 2011; 76(3-5): p.323-333.

47. Liu L, Celma CCP, Roy P. Rift Valley fever virus structural proteins: expression, characterization and assembly of recombinant proteins. Virology Journal. 2008; 5: p.82.

48. Habjan M, Penski N, Wagner V, et al. Efficient production of Rift Valley fever virus-like particles: The antiviral protein MxA can inhibit primary transcription of bunyaviruses. Virology. 2009; 385(2): p.400408.

49. Branco LM, Grove JN, Geske FJ, et al. Lassa virus-like particles displaying all major immunological determinants as a vaccine candidate for Lassa hemorrhagic fever. Virology Journal. 2010; 7: p. 279.

50. Schlie K, Maisa A, Freiberg F, et al. Viral Protein Determinants of Lassa Virus Entry and Release from Polarized Epithelial Cells. Journal of Virology. 2010; 84(7): p.3178-3188. 